\title{
МЕДИЧНІ КОМУНІКАТОРИ ДЛЯ СІМЕЙНОЇ МЕДИЦИНИ
}

\author{
В. О. Романов, Т. В. П'ятчанінаㄹ, О. В. Ковирьова \\ Інститут кібернетики імені В. М. Глушкова НАН України \\ ${ }^{1}$ Інститут експериментальної патології, онкології і радіобіології \\ імені Р. Є. Кавецького НАН України
}

\begin{abstract}
Оцінювання адекватного рівня стану здоров'я пацієнтів і ефективності методів лікування вимагає сучасних клінічних досліджень «якості життя» шляхом використання різноманітних стандартизованих опитувальників як загального призначення, так і створених для окремих нозологій. Оцінювання якості життя, що здійснюється самим пацієнтом із використанням анкет-опитувальників, разом із традиційним медичним висновком лікаря, дає повну й об'єктивну характеристику стану пацієнта. Тому мета роботи полягала у розробленні програмних засобів автоматизації оцінювання якості життя на основі стандартизованого опитувальника MOS SF-36 для мобільного планшетного комп'ютера з використанням результатів у якості інорормаційної підтримки прийняття об'єктивних лікарських рішень.

В якості прототипу взято медичний інформаційний комунікатор розробки Інституту кібернетики імені В. М. Глушкова НАН України та Національної медичної академії післядипломної освіти імені П. Л. Шупика (МОЗ України) на базі мобільного планшетного комп'ютера, програмне забезпечення якого містить п'ять підсистем із певним набором довідниково-інформаційних фрункцій для підтримки та супроводу діяльності лікаря й інтерактивного спілкування з пацієнтом, зокрема, у випадку обмеження його комунікативних можливостей у результаті захворювання.

Проведений аналіз предметної області поширених стандартизованих опитувальників для оцінювання якості життя пацієнтів виявив оптимальний для проведення автоматизації - The Medical Outcomes Study Short Form (MOS SF-36) - коротка фрорма неспецифрічного опитувальника для визначення якості життя, для якої існує україномовна адаптована версія. Здійснено початковий етап розробки програмних засобів автоматизації оцінювання якості життя на основі стандартизованого опитувальника MOS SF-36 для мобільного планшетного комп'ютера, результати якого можуть слугувати інформаційним супроводом прийняття обґрунтованих лікарських рішень.
\end{abstract}

Ключові слова: інформаційні комунікатори, якість життя, сімейна медицина, спеціалізоване програмне забезпечення, SF-36.

\section{MEDICAL COMMUNICATORS FOR FAMILY MEDICINE}

\author{
V. O. Romanov, T. V. Pyatchanina ${ }^{1}$, O. V. Kovyrova \\ V. M. Glushkov Institute of Cybernetics, NAS of Ukraine \\ ${ }^{1}$ R. E. Kavetsky Institute of Experimental Pathology, Oncology and Radiobiology, NAS of Ukraine
}

\begin{abstract}
Background. Assessing the adequate level of health of patients and the effectiveness of treatment methods requires modern clinical studies of «quality of life» through the use of various standardized questionnaires, both general purpose and designed for individual nosologies. The assessment of quality of life, which is performed by the patient using questionnaires, together with the traditional medical opinion of the doctor, gives a complete and objective description of the patient's condition. The goal is to develop software to automate quality of life assessment based on the standardized MOS SF-36 questionnaire for a mobile tablet computer using the results as information support for making objective medical decisions.

Materials and methods. The method of estimating the quality of life according to the MOS SF-36 questionnaire is based on the instruction for calculating the indicators of quality of life, for which an applied computer program has been developed. This applied computer program calculates quality of life indicators on 8 scales. To estimate by a family doctor or general doctor the quality of life with supporting the proposed medical communicator there were used Java programming language and integrated environment Android Studio 3.6.3, which provides storage of survey data and calculated indicators of quality of life on recommended scales. An appropriate database has been created.

Results. The prototype was a medical information communicator based on a mobile tablet computer (V. M. Glushkov Institute of Cybernetics of NASU and Shupyk National Medical Academy of Postgraduate Education), the software of which contains five subsystems with a set of reference and information functions to support the activities of the doctor and interactive communication with the patient, in particular, in case of limitation of his communication capabilities as a result of the disease or trauma.

Conclusions. The analysis of the subject area of common standardized questionnaires to assess the quality of life of patients revealed the optimal for automation - The Medical Outcomes Study Short Form (MOS SF-36) - a short form of non-specific questionnaire for quality of life, for which there is a Ukrainian-adapted version. The initial stage of development of software for automation of quality of life assessment based on the standardized questionnaire MOS SF-36 for mobile tablet computer, the results of which can serve as information support for making informed medical decisions, has been completed.
\end{abstract}

Key words: information communicators, quality of life, family medicine, speciality application-dependent software, SF-36. 


\title{
МЕДИЦИНСКИЕ КОММУНИКАТОРИ ДЛЯ СЕМЕЙНОЙ МЕДИЦИНИ
}

\author{
В. А. Романов, Т. В. Пятчанина ${ }^{1}$, А. В. Ковырева \\ Институт кибернетики имени В. М. Глушкова НАН Украины \\ 1 Институт экспериментальной патологии, онкологии и радиобиологии \\ имени Р. Е. Кавецкого НАН Украины
}

\begin{abstract}
Оценивание адекватного уровня состояния здоровья пациентов и эффрективности методов лечения требует современных клинических исследований «качества жизни» путем использования различных стандартизированных вопросников как общего назначения, так и предназначенных для отдельных нозологий. Оценка качества жизни, которая осуществляется самим пациентом с использованием анкет-вопросников, вместе с традиционным медицинским заключением врача дает полную и объективную характеристику состояния больного. Поэтому цель работы состояла в разработке программных средств автоматизации оценивания качества жизни на основе стандартизированного вопросника MOS SF-36 для мобильного планшетного компьютера с использованием результатов в качестве инфрормационной поддержки принятия объективных врачебных решений.

В качестве прототипа был взят медицинский инорормационный коммуникатор разработки Института кибернетики имени В. М. Глушкова НАН Украины и Национальной медицинской академии последипломного образования имени П. Л. Шупика (МЗ Украины) на базе мобильного планшетного компьютера, программное обеспечение которого содержит пять подсистем с определенным набором справочно-инорормационных фрункций для поддержки и сопровождения деятельности врача и интерактивного общения с пациентом, в частности, в случае ограничения его коммуникативных возможностей, вызванных болезнью или травмой.

Проведенный анализ предметной области распространенных стандартизированных вопросников для оценки качества жизни пациентов позволил выбрать оптимальный, пригодный для автоматизации - The Medical Outcomes Study Short Form (MOS SF-36), представляющий собой краткую фрорму неспецисрического вопросника для определения качества жизни с адаптированной версией на украинском языке. Осуществлен начальный этап разработки программных средств автоматизации оценивания качества жизни на основе стандартизированного вопросника MOS SF-36 для мобильного планшетного компьютера, результаты которого могут служить информационным сопровождением принятия обоснованных врачебных решений.
\end{abstract}

Ключевые слова: инсрормационные коммуникаторы, качество жизни, семейная медицина, специализированное программное обеспечение, SF-36. 
Вступ. В останні роки оцінювання адекватного рівня стану здоров’я пацієнтів і ефективності методів лікування вимагає клінічних досліджень «якості життя» (ЯЖ) шляхом використання різноманітних опитувальників, попри відсутність загальноприйнятого визначення цього поняття [1]. В сучасній медицині широко використовується термін «health related quality of life» (якість життя, пов'язана зі здоров'ям), де, за визначенням ВООЗ, під здоров’ям розуміється повне фізичне, соціальне та психічне благополуччя, а не тільки відсутність хвороб або фізичних дефектів [2]. Отже, ЯЖ, пов'язана зі здоров'ям, є невід'ємною частиною сучасної медицини, а оцінювання ЯЖ, що здійснюється пацієнтом із використанням анкет-опитувальників, як доповнення до традиційного медичного висновку лікаря, дозволяє скласти повну й об'єктивну характеристику стану здоров'я. Прицьому, важливою є суб'єктивність процедури оцінювання самим пацієнтом за відсутності професійного впливу медичних працівників та думки оточуючих.

Опитувальники, що є основними інструментами оцінювання ЯЖ, і яких на сьогоднішній день нараховують понад 150 різновидів, поділяють на загальні, що застосовують при різних захворюваннях та спеціальні - для конкретних нозологій. Вибір опитувальника залежить від мети дослідження та від інших факторів, як то: вік пацієнта, стан здоров’я тощо. Для вітчизняних досліджень ЯЖ застосовують іноземні опитувальники. Питання перекладу й адаптації анкет вирішується, зазвичай, компаніями-розробниками за участі міжнародних експертів.

До найважливіших сфер застосування оцінювання ЯЖ у практиці охорони здоров’я відносяться такі: отримання об'єктивної інформації про стан здоров'я пацієнта, його працездатності; отримання даних про зміни в стані пацієнта під час довготривалої хронічної хвороби; для оцінювання ефективності терапії; для визначення оптимальності лікувальних засобів із точки зору співвідношення ціна - якість; для клінічних випробувань; для оцінювання ефективності медичної допомоги в цілому.

До числа найбільш використовуваних у світовій медичній практиці відносяться опитувальники: Quality of Well-Being (QWB) Index, Sickness Impact Profile (SIP), Nottingham Health Profile (NHP), Quality of Life Index (QLI), MOS 36-Item Short-Form Health Survey (MOSSF-36).

The Medical Outcomes Study Short Form (MOS SF36) - коротка форма неспецифічного опитувальника для визначення ЯЖ, для якої існує україномовна адаптована версія, створена за допомогою методології міжнародного проєкту оцінювання ЯЖ IQOLA [3]. Анкета-опитувальник SF-36 складається з 36 питань, об’єднаних у 8 шкал, що призвані віддзеркалювати: фізичну активність (Physical Functioning), роль фізичних проблем в обмеженні життєдіяльності (Role Physical Functioning), біль (Bodily Pain), життєздатність (Vitality), соціальну активність (Social Functioning), роль емоційних проблем в обмеженні життєдіяльності (Role Emotional), психічне здоров'я (Mental Health), загальне здоров’я (General Health). Також є додаткова 9 шкала - стан здоров'я в порівняні 3 минулорічним [3]. Шкали групуються за двома показниками «фізичний компонент здоров'я» (Physical Component Summary) - фізична активність; роль фізичних проблем в обмеженні життєдіяльності; біль; загальне здоров'я та «психологічний компонент здоров'я» (Mental Component Summary) - життєздатність; соціальна активність; роль емоційних проблем в обмеженні життєдіяльності; психічне здоров’я. Показники кожної шкали можуть приймати значення від 1 до 100, де 100 — це повне здоров'я. Результати формуються у вигляді оцінок у балах за 8 шкалами, які складені таким чином, що більш висока оцінка вказує на більш високий рівень ЯЖ.

Стандартизоване оцінювання ЯЖ здійснюється шляхом самостійного 10-15 хвилинного анкетування пацієнтами за отриманою згодою [4] після пояснення правил заповнення. Пацієнти з вадами зору тощо отримують допомогу лікаря шляхом прямого опитування ним та надають йому усні відповіді. Оцінювання результатів здійснюється за відсутності пацієнта.

Сучасний стан ринку мобільних пристроїв характеризується домінуючою тенденцією до зростання кількості користувачів Smartphone та Tablet PC. Функціональні можливості дозволяють використовувати їх у якості потужного інструменту, зокрема, в системі охорони здоров'я. Ця тенденція реалізується в стрімкому розвитку нових напрямів інформаційних технологій, таких як mHealth або eHealth, основна ідея яких полягає в розширенні можливостей закладів охорони здоров'я, медичних працівників, а також і громадян в управлінні медичними даними, що в перспективі спрямовано на поліпшення показників здоров’я населення, ефективності роботи медичного персоналу та підвищення рентабельності систем охорони здоров'я.

Слід зазначити, що на сьогоднішній день існують перші спроби створення прототипу мобільного застосування для оцінювання ЯЖ у онкологічних пацієнтів із використанням опитувальника Quality of Life Questionnaire-Core 30 (QLQ-C30; German version 3) 
Європейської організації з досліджень та лікування paкy (European Organization for Researc hand Treatment of Cancer (EORTC) [5], та на базі опитувальників EORTC QLQ C-30 i QLQ BR23 для оцінювання ЯЖ у пацієнтів на рак молочної залози в складі мобільного додатку [6], проте, в Україні відчувається недостатність програмних засобів експертного оцінювання результатів індивідуальних опитувань, що зменшує можливості сімейних лікарів використовувати сучасні ефективні інструменти для оцінювання стану пацієнта та вироблення обгрунтованих об’єктивних рішень.

Мета роботи: розробка апаратних і програмних засобів автоматизації оцінювання якості життя на основі стандартизованого опитувальника MOSSF-36 для мобільного планшетного комп’ютера з використанням результатів у якості інформаційної підтримки прийняття об’єктивних лікарських рішень.

Матеріали та методи дослідження. В основу методу оцінки якості життя за опитувальником MOS SF-36 покладено інструкцію розрахунку показників якості життя, для якої розроблено прикладну комп’ютерну програму. Ця комп’ютерна програма здійснює обчислення показників якості життя за 8 шкалами. Для оцінювання якості життя сімейним лікарем за допомогою запропонованого медичного комунікатора використано мову програмування Java та інтегроване середовище розробника Android Studio 3.6.3, на базі яких забезпечується зберігання даних опитування та розрахованих показників якості життя за рекомендованими шкалами. Для цього створено відповідну базу даних.

Результати та їх обговорення. Для реалізації мети використовували розроблений в Інституті кібернетики імені В. М. Глушкова НАН України та Національній медичній академії післядипломної освіти імені П. Л. Шупика на базі мобільного планшетного комп’ютера медичний інформаційний комунікатор [7] із набором прикладних програм та алгоритмів [8, 9]. Спеціалізоване програмне забезпечення інформаційного комунікатора містить п’ять підсистем, кожна 3 яких виконує певний набір функцій. Перша програмна підсистема призначена для першого контакту та служить для надання лікарю детальної інформації про захворювання або травму, відповідні методи догляду або лікування при першому огляді пацієнта або постраждалого. Друга підсистема побудована з урахуванням існуючих у сімейній медицині стандартів і протоколів. Третя підсистема відображає основні положення щодо існуючих правових норм у діяльності сімейного лікаря. Четверта підсистема присвячена фармацевтичному забезпеченню в діяльності сімейного лікаря. П'ята програмна підсистема інформаційного медичного комунікатора призначена для забезпечення альтернативного спілкування з пацієнтами, які тимчасово або назавжди втратили можливість говорити.

Для використання комунікатора як експертної системи для оцінювання якості життя нами побудовано iї структуру (рис. 1). Робота системи базується на використанні опитувальників різного призначення. Компонентами системи є «Пацієнт», «Лікар», «Програмна складова», «Інформаційна складова». Програмна складова містить модулі «Інтерфейс пацієнта», «Опитувальник», «Оцінка відповідей», «Виведення результату», «Пояснення та/або рекомендації». Інформаційна складова містить «Базу знань» та «Інтерфейс лікаря». Пацієнт має доступ до «Інтерфейсу пацієнта», а лікар у свою чергу до «Інтерфейсу лікаря». Отже, забезпечується взаємодія лікаря з пацієнтом. Передбачено одночасний доступ до системи декількох користувачів або лікарів і можливість у разі потреби обирати необхідний опитувальник.

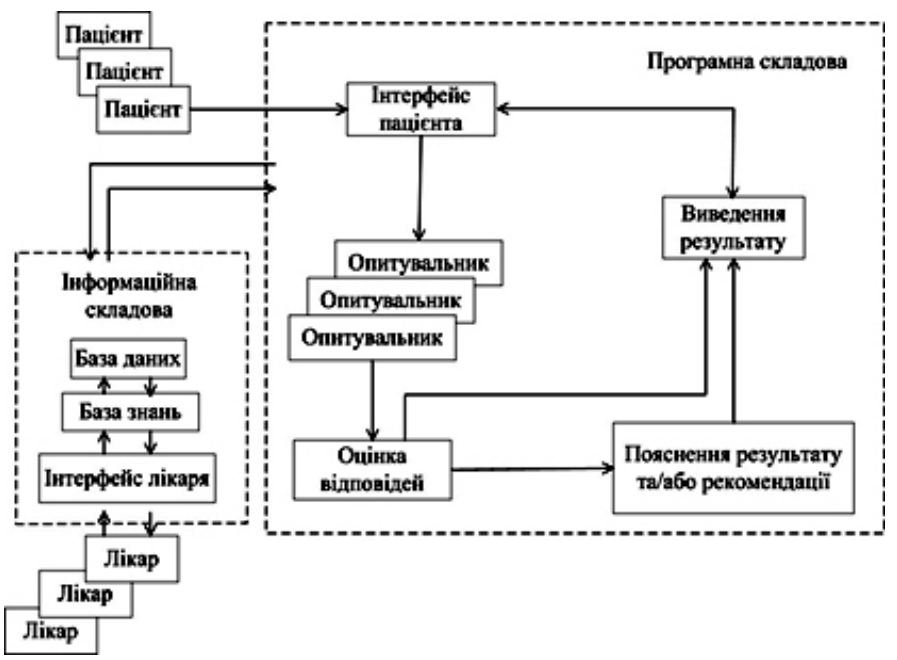

Рис. 1. Структура медичної діагностичної експертної системи 
Розроблені програми призначені для використання на операційній системі Android, що підтримують опитувальник SF-36. Передбачено два режими роботи з комунікатором: режим пацієнта та режим лікаря.

Інтерфейс пацієнта (рис. 2) призначений для проведення опитування та підтримує зберігання

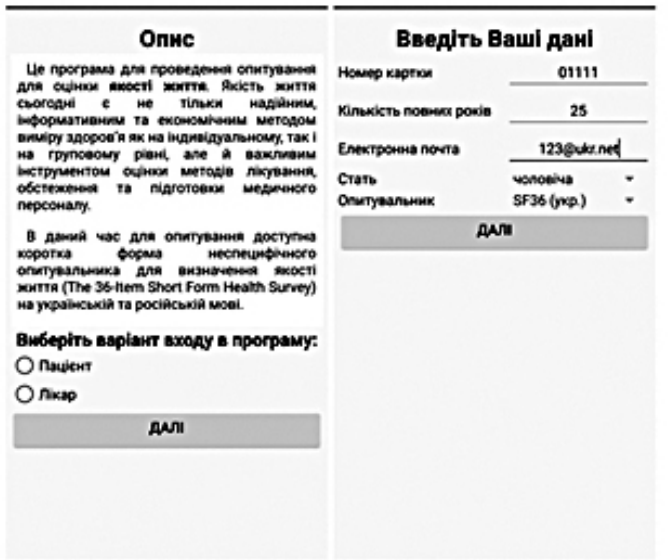

Рис. 2. Інтерфейс пацієнта

Інтерфейс лікаря (рис. 3) дозволяє отримати дані про пацієнтів, які пройшли опитування за допомогою комунікатора, та виконати сортування (оцінювання) за різними критеріями. такої інформації про пацієнта: номер електронної картки, адреса електронної пошти, дані про вік, стать та результати опитування. Результати можуть бути надіслані лікарю на електронну пошту або збережені у вигляді pdf-файлу на комунікаторі лікаря.
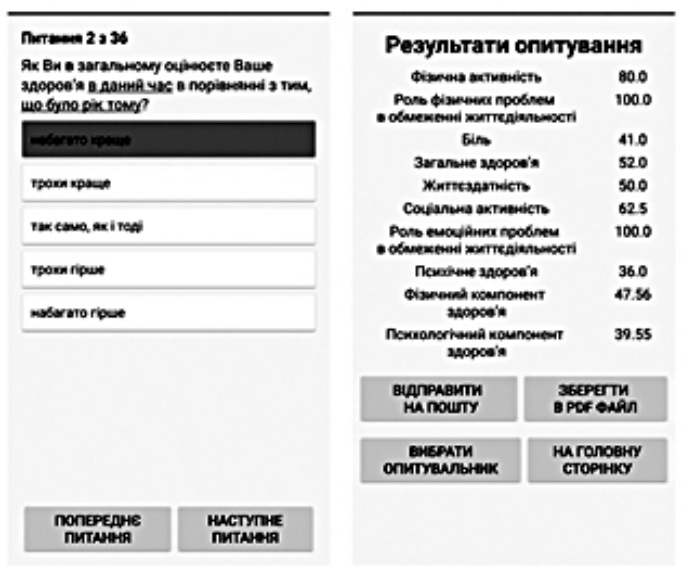

Інформація про оцінювання якості життя може бути отримана у вигляді csv-файлу та використана для подальшого аналізу чи надання відповідної рекомендації пацієнту щодо подальших дій.

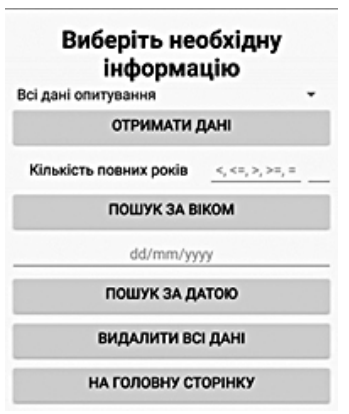

Рис. 3. Інтерфейс лікаря

Висновки. Проведено аналіз предметної області загальноприйнятих стандартизованих опитувальників для оцінювання якості життя пацієнтів із різними нозологіями з метою вибору оптимального опитувальника для автоматизації оцінювання фізичної, соціальної активності, болю, життєздатності, психічного здоров'я, ролі емоційних проблем в обмеженні життєдіяльності. Виявлено, що найбільш релевантною являється стандартизована анкета опитувальник EORTC The Medical Outcomes Study Short Form (MOS SF-36) (україномовна версія).

Здійснено початковий етап розробки програмних засобів автоматизації оцінювання якості життя на основі стандартизованого опитувальника MOSSF-36 для мобільного планшетного комп’ютера, результати якого можуть слугувати інформаційним супроводом прийняття обгрунтованих лікарських рішень.

Перспективи подальших досліджень. Передбачено можливість розширення переліку стандартних опитувальників із відповідним експертним оцінюванням результатів, а також можливість зберігання даних у спеціалізованому сервері медичної установи з віддаленим доступом. Також, передбачено реалізацію версії комунікатора на базі смартфону для дистанційного оцінювання якості життя. 


\section{Література.}

1. Romero M. Is Health Related Quality of Life (HRQoL) a valid indicator for health systems evaluation? / Romero M., Vivas-Consuelo D., Alvis-Guzman N. // SpringerPlus. — 2013. — № 2. — P. 664-671.

2. WHO: Constitution of the World Health Organization. In: WHO: Basic Documents Forty-Seventh Edition. Geneva: World Health Organization, 2009. — P. 1-5.

3. Бабійчук Ю. В. Динаміка первинної інвалідності, фактори ризику ії̈ виникнення, показники якості життя хворих бронхіальною астмою [Текст] : дис. ... канд. мед. наук: 14.01.27 / Бабійчук Юрій Валерійович ; Вінницький національний медичний ун-т ім. М. I. Пирогова. - Вінниця, 2002. - 143 с.

4. Іванюк Н. Б. Предиктори покращення систолічної функції лівого шлуночка та якості життя у пацієнтів 3 ішемічною хворобою серця і серцевою недостатністю після реваскуляризації міокарда [Текст] : автореф. дис. ... канд. мед. наук : 14.01.11 / Іванюк Наталія Борисівна; Нац. мед. акад. післядиплом. освіти імені П. Л. Шупика. - К., 2017. — 24 с. : рис.

5. Kessel K.A, Vogel M. M E, Alles A., Dobiasch S., Fischer H., Combs S. E. Mobile App Delivery of the EORTC QLQ-C30 Questionnaire to Assess Health-Related Quality of Life in Oncological Patients: Usability Study / // JMIR Mhealth Uhealth. - 2018. - T. 6, № 2 (e45). - Р. 1-8.

6. mHealth-додаток для управління медичними даними хворих на рак молочної залози / Куліков В. М., Дворщенко О. С., П’ятчаніна Т. В., Кравчук В. В. // Укр. радіол. журн. - 2016. - Спец. вип. № 1. - С. 201.

7. Патент України на корисну модель № 80490. Спосіб спілкування з людиною, що має мовні та слухові обмеження / Сергієнко І. В., Вороненко О. В., Галелюка І. Б., Романов В. О. - Бюл. № 10, 27.05.2013.

8. Свідоцтво про реєстрацію авторського права на твір «Комп’ютерна програма «Допомога у спілкуванні 3 людиною, що має мовні та слухові обмеження» № 62686 від 26.11.2015 / Мінцер О. П., Романов В. О., Галелюка І. Б.

9. Свідоцтво про реєстрацію авторського права на твір «Комп’ютерна програма «Порядок дій при наданні невідкладної медичної допомоги» № 62687 від 26.11.2015 / Мінцер О. П., Романов В. О., Галелюка I. Б.

\section{References.}

1. Romero, M., Vivas-Consuelo, D., Alvis-Guzman, N. (2013). Is Health Related Quality of Life (HRQoL) a valid indicator for health systems evaluation? SpringerPlus, 2 (1), 664-71.

2. WHO: Constitution of the World Health Organization (2009). In: WHO: Basic Documents Forty-Seventh Edition. Geneva: World Health Organization, 1-5.

3. Babiichuk, Y. V. (2002). Dynamika pervynnoi invalidnosti, faktory ryzyku yii vynyknennia, pokaznyky yakosti zhyttia khvorykh bronkhialnoiu astmoiu: dys. ... kand. med. nauk: 14.01.27 [Dynamics of primary disability, risk factors for its occurrence, indicators of quality of life of patients with bronchial asthma: dis . cand. med. sciences: 14.01.27]. Babiichuk Yurii Valeriiovych ; Vinnytskyi natsionalnyi medychnyi un-t im. M. I. Pyrohova [Babiychuk, Yuriy Valeriyovych, National Pirogov Medical University], 143.

4. Ivaniuk, N. B. (2017). Predyktory pokrashchennia systolichnoi funktsii livoho shlunochka ta yakosti zhyttia u patsiientiv z ishemichnoiu khvoroboiu sertsia i sertsevoiu nedostatnistiu pislia revaskuliaryzatsii miokarda: avtoref. dys. ... kand. med. nauk : 14.01.11 [Predictors of improvement of left ventricular systolic function and quality of life in patients with ischemic heart disease and heart failure after myocardial revascularization: author's ref. dis. ... cand. med. sciences: 14.01.11]. Ivaniuk Nataliia Borysivna ; Nats. med. akad. pisliadyplom. osvity im. P. L. Shupyka [Ivanyuk Natalia Borysivna; Shupyk National Medical Academy of Postgraduate Education], 24 : rys.

5. Kessel, K. A., Vogel, M. M., Alles, A., Dobiasch, S., Fischer, H., Combs, S. E. (2018). Mobile App Delivery of the EORTC QLQ-C30 Questionnaire to Assess Health-Related Quality of Life in Oncological Patients: Usability Study. JMIR mHealth and uHealth, 6 (2), e45.

6. Kulikov, V. M., Dvorshchenko, O. S., Piatchanina, T. V., Kravchuk, V. V. (2016). mHealth-dodatok dlia upravlinnia medychnymy danymy khvorykh na rak molochnoi zalozy [Kulikov V.M., Dvorshchenko O.S., Pyatchanina T.V., Kravchuk V.V. mHealth-application for managing medical data of patients with breast cancer]. Ukr. radiol. zhurn. (Ukr. radiol. magazine), 1, 201.

7. Patent Ukrainy na korysnu model № 80490. Sposib spilkuvannia z liudynoiu, shcho maie movni ta slukhovi obmezhennia / Sergienko, I. V., Voronenko, O. V., Galelyuka, I. B., Romanov, V. O. [Sergienko I.V., Voronenko O.V., Galelyuka I.B., Romanov V.O. (2013). Patent of Ukraine \# 80490 «Method of communication with person with voice and auditory limitation»]. Bull., 10, 27.05.2013.

8. Svidotstvo pro reiestratsiiu avtorskoho prava na tvir «Kompiuterna prohrama «Dopomoha u spilkuvanni z liudynoiu, shcho maie movni ta slukhovi obmezhennia» [Copyright certificate for software «Software for communication with a person with speaking and hearing limitation»], \# 62686, 26.11.2015 / Mintser, O. P., Romanov, V. O., Galelyuka, I. B.

9. Svidotstvo pro reiestratsiiu avtorskoho prava na tvir «Kompiuterna prohrama «Dopomoha u spilkuvanni z liudynoiu, shcho maie movni ta slukhovi obmezhennia» [Copyright certificate for software «Software for providing procedures for the emergency medical care»], \# 62686, 26.11.2015 / Mintser, O. P., Romanov, V. O., Galelyuka, I. B. 